\title{
ANOTACIONES AL POEMA \\ EXHORTACIÓN A UNA NAVE NUEVA \\ AL ENTRAR EN EL AGUA, DE FRANCISCO DE QUEVEDO
}

El primer precedente que viene a la memoria cuando se analiza la "Exhortación a una nave nueva al entrar en el agua", de Francisco de Quevedo, es la famosa oda 14 del libro 1 de Horacio: "O navis, referent in mare te novi". En ambos casos, el poeta se dirige a una embarcación advirtiéndole sobre los peligros del mar. Pero en Horacio no se trata de una "nave nueva", sino de un barco que ha navegado mucho, al cual exhorta a no entregarse al capricho de los vientos, no confiar en "su nombre y su linaje" y a buscar la seguridad del puerto. Quintiliano propuso una interpretación simbólica de esta oda, según la cual "la nave significa el estado, las olas y las tempestades las guerras civiles y el puerto la paz y la concordia"l. El texto no muestra las claves de tal alegoría, y por ello esta interpretación ha sido discutida por comentaristas de todas las épocas. Sin embargo, hay varias razones que inclinan a pensar en la intención política del poema. En la estrofa última, se dice: "Nuper sollicitum quae mihi taedium, / nunc desiderium curaque non levis...”. Estas palabras producen unas resonancias que no acaban de tener sentido si se toman literalmente. Pero sobre todo lo que ocurre es que, aunque la interpretación alegórica de tema político no brote del poema de una manera inmediata y evidente, una vez sugerida se ve que se adecua perfectamente a todos los elementos y aspectos del texto.

En el Siglo de Oro hubo varias traducciones de esta oda de Horacio. En la edición de la poesía de Francisco de la Torre, que publicó Quevedo en 1631, hay un apéndice donde figura el testimonio de un curioso certamen: el poema de Horacio que nos ocupa en tres traducciones distintas, debidas a la pluma de Juan de Almeida, de Alonso de Espinosa y del Brocense. Se reproduce también una carta, escrita en un tono de amistoso desenfado, en la que los tres traductores se dirigen a fray Luis de León pidiéndole su dictamen sobre las distintas

\footnotetext{
${ }^{1}$ Quintiliano, Institutio oratoria, ed. S. Corsi, Rizzoli, 1997, VIII, 6, 44.
} 
versiones. Fray Luis responde elogiando las tres pero enviando otra traducción hecha por él, la cual, según dice, había llevado a cabo en una sola noche. Años después, Esteban Manuel de Villegas hizo una nueva versión, que figura en sus Eróticas o amatorias (1617). Asimismo, hay que recordar un poema de Francisco de Figueroa que, aunque no es propiamente una traducción, ni siquiera dándole a este término la amplitud que poseía en la época, toma como punto de partida la oda de Horacio para hacer sobre ella una serie de variaciones y prolongaciones. Pero en este caso el símbolo se proyecta más hacia la meditación sobre la vida individual que hacia la realidad política. Como dice Mercedes López Suárez, Figueroa "concentra en la contemplación de la 'navecilla', como amplificatio de la oda 14, libro 1 de Horacio, su meditación vital, que tiñe un sentimiento nostálgico sobre el paso inexorable del tiempo, la senectud, la desilusión y, en definitiva, como ya se ha observado, su taedium vitae" ${ }^{2}$.

De hecho, la navegación, por lo que su realidad ha supuesto en la experiencia de los hombres, aparece, en todas las épocas y culturas, como trasunto de los peligros que se ciernen sobre la existencia de los mortales. Como dice un emblematista del siglo XVII, "es el mar el símbolo más claro para representar el mundo que habitamos... Son los bajeles que en él navegan los hombres que en el mundo habitan y las angustias que continuamente nos cercan son los naufragios que allí cada instante se recelan"3. De ahí el valor de la navegación en la poesía de tema religioso como imagen de la vida del alma, asediada por engaños y tentaciones, y siempre en pos del puerto de la salvación o, en otro contexto, como signo de las tribulaciones del hombre enamorado que se debate en el piélago de sus pasiones ${ }^{4}$. Pero en la tradición clásica la idea de la navegación adquirió un valor más concreto. Se suponía que una de las características de la Edad de Oro es que en ella no existían los barcos, pues cada cual era feliz sin moverse del lugar en donde había nacido y sin ambicionar nada. Luego, la avidez de riquezas y el deseo de metales preciosos hizo que los mortales desearan conocer y descubrir tierras extrañas, con lo que se inician los viajes por mar. Así, el hombre, empujado por la avaricia, crea un nuevo género de muerte y empiezan las guerras entre pueblos que antes estaban separados por las fronteras infranqueables de las aguas. En esa medida, la navegación aparece con connotaciones negativas que se hallan, sin duda, entre los presupuestos de este poema de Quevedo.

${ }^{2}$ En su ed. de la Poesía de Francisco de Figueroa, Cátedra, Madrid, 1989, p. 488

${ }^{3}$ Antonio de Lorea en A.B. Vistarini y John T. Cull, Emblemas españoles ilustrados, Akal, Madrid, 1999, p. 566.

${ }^{4}$ Sobre este tema, véase Pilar Manero Sorolla, Imágenes petrarquistas en la lírica del Renacimiento, PPU, Barcelona, 1990, pp. 200-250. 
Dentro del tema de la condena de la navegación, muy frecuente en la literatura clásica y en la del Siglo de Oro, hay un motivo que se repite a menudo, y consiste en la contraposición entre el árbol arraigado y el árbol cortado, convertido en tablas, mástiles y remos. Con ello se expresa el contraste entre la paz del que permanece en tierra sin moverse y los peligros de la navegación. Así lo vemos en los primeros versos de la Medea de Eurípides: “;Ojalá la nave de Argos no hubiera volado sobre las sombrías Simplégades hacia la tierra de Cólquide, ni en los valles del Pelión hubiera caído el pino cortado por el hacha, ni hubiera provisto de remos las manos de los valerosos hombres que fueron a buscar para Pelias el vellocino de oro!". En un poema dedicado a una barca, Catulo recuerda también su procedencia del árbol: "post paphaselus antea fuit / comata silva" y luego, dirigiéndose al monte Cítoro, donde se supone que crecía dicho árbol, dice: "ultima ex origine / tuo stetisse dicit in cacumine" (vv. 15-17). Ovidio, hablando de la Edad de Oro, dice que "nondum... / in liquidas pinus descenderat undas" ${ }^{\prime \prime}$, y luego caracteriza a la Edad de Hierro porque "quaeque diu steterant in montibus altis, / fluctibus ignotis exsultavere carinae" (Metamorfosis, I, 133-135). Esta contraposición entre el árbol y el navío aparece también en la poesía del Siglo de Oro: "El verde robre, que es barquillo ahora"; "Mejor fueras, oh pino vagabundo, / vestido de hojas en el monte altivo, / del sol ardiente vencedor fecundo, / que tronco estéril, pies de un fugitivo"; "ausente yace de la selva cara, / do el verde ornato conservar pudiera" " "Turbó la paz segura / con que en la antigua selva florecieron / el abeto y el pino, / y trájolos al puerto, / y por campos del mar les dio camino"10; "lo que es leño en la mar, es aquí haya"11; "De selva nieto fue, para ser hijo / de artífice prolijo, / bajel que ya cascado / se queja"12. Más adelante citaremos otros ejemplos de Carrillo y Sotomayor, de F. de Rioja y del Príncipe de Esquilache.

Joseph Fucilla observa de pasada que la "Exhortación a una nave nueva" de Quevedo "is obviously derived from the composition in

${ }^{5}$ Catulo, Poésies, ed. G. Lafaye, Les Belles Lettres, Paris, 1982, IV, 10-11.

${ }^{6}$ Ovidio, Metamorfosis, ed. A. Ruiz de Elvira, Alma Mater, Barcelona, 1964, I, 94-95.

7 Luis de Góngora, Soledades, ed. R. Jammes, Castalia, Madrid, 1994, t. 2, v. 38.

${ }^{8}$ Francisco de Borja, Príncipe de Esquilache, Nápoles recuperada, BAE, Madrid, 1948, p. 292.

9 JuAn de Jáuregui, “A un navío destrozado en la ribera del mar", Obras, ed. I. Ferrer de Alba, Espasa-Calpe, Madrid, 1973, t. 1, p. 30.

${ }^{10}$ Francisco de Rioja, Poesía, ed. B. López Bueno, Cátedra, Madrid, 1984, p. 172.

11 Pedro Espinosa, Poesías completas, ed. F. López Estrada, Clásicos Castellanos, Madrid, 1975, p. 145.

${ }_{12}$ Esteban Manuel de Villegas, Eróticas o amatorias, ed. N.A. Cortés, EspasaCalpe, Madrid, 1969, p. 25. 
the Greek Anthology on the subject, or one of its imitations" y señala entre ellas un poema de Groto $^{13}$. Hay efectivamente varios epigramas griegos que tratan el tema del árbol y la nave, la mayoría de ellos sobre un árbol que fue arrancado por el huracán y luego, convertido en nave, se ve obligado a seguir sufriendo la cólera del viento ${ }^{14}$.

Fui pianta in alto, or l'alto solco trave, porto vele e sarte or, già portai fronde.

Già fui d'augelli, or son d'uomini grave, già di rami, or di remi orno le sponde. Stetti arbor fisso, or vo veloce nave, già fui de' venti, or son gioco de l'onde. Già del cielo, or del mar, l'acqua ho nemica, così fin non ha mai la mia fatica

(L. Groto, "Nave", Rime, parte prima, p. 70).

Como se ve, se trata de un conjunto de variaciones ingeniosas sobre la contraposición entre el árbol y el navío, como en Quevedo, pero mientras Groto hace mero alarde sin mayor trascendencia, la "Exhortación" extrae de este tema una serie de consideraciones sobre la seguridad y el peligro, sobre la prudencia y la avaricia, con lo cual se sitúa en la tradición poética de la navegación como tema de sentido moral y filosófico. Llama la atención, sin embargo, el hecho, no demasiado frecuente en la literatura del Siglo de Oro, de que el poema de Quevedo se basa en una imagen o idea que funciona como símbolo sin que su valor sea puesto en evidencia ni mostrado como tal por el texto. Es decir, que el poema, como la oda de Horacio, consta sólo del plano simbólico, sin que el significado se haga explícito en ningún momento ${ }^{15}$. O quizá mejor, podríamos decir que el poema habla sobre la navegación en sentido estricto, como producto de la ambición humana y como riesgo que el hombre se empeña en correr sin necesidad alguna. Al mismo tiempo, y sin abandonar el plano literal, esta realidad se trasciende para adquirir un valor más amplio, y para aparecer como trasunto de algunas dimensiones generales de la existencia, fundamentalmente de la idea, de raigambre clásica, según

13 Joseph G. Fucilla, "Some imitations of Quevedo and some poems wrongly attributed to him", The Romanic Review, 21 (1930), p. 234.

${ }^{14}$ Véase Antología griega, ed. W.R. Paton, Harvard University Press, 1983, libro IX, núms. 30, 31, 105, 131, 376. Quevedo podía conocer este último en la traducción de Thomas More que figura, entre otros epigramas, en algunas ediciones de la Utopia.

${ }^{15}$ Un caso semejante, como ha observado A. Rey, es el del soneto de Quevedo que comienza: "De amenazas del Ponto rodeado", donde sólo el título se refiere al nivel simbólico de la imagen, pero en cuyo texto "no se menciona el plano imaginario que se corresponde con el real" (Poesía moral. Polimnia, ed. A. Rey, Tamesis, Madrid, 1992, p. 231). 
la cual es el hombre el que con su ambición y desmesura frustra sus anhelos de felicidad y se labra su desgracia. Pero no habría realmente en este poema dos niveles, uno literal y otro simbólico, con el salto cualitativo que ello implica, sino una transición paulatina que proyecta lo particular hacia lo universal sin solución de continuidad. El hecho de que el barco sea el interlocutor y de que el poema esté lleno de rasgos mediante los que se personifica al navío, contribuye, como ocurre también en Horacio, a crear esta aura simbólica.

En la poesía contemporánea de Quevedo, encontramos pocos poemas que desarrollan el mismo tema. Uno de ellos, el de Luis Carrillo y Sotomayor, que comienza: “¡Oh tú, detén el paso...!”16, está dirigido no al barco, sino al hombre que se dispone a navegar en él: "Antes que entregues, ciego, a un mar airado / cuanto manso le ves, tu navecilla...". A este interlocutor se le muestran, como ejemplo disuasorio, los restos de otra embarcación en la que ha naufragado el sujeto poético. A pesar de que las imágenes náuticas llenan el poema, hay una frase, una sola en todo el texto, que parece conferir a la composición un significado amoroso: "Cual tú, hermoso mar de hermosos ojos / hallé; dichosa se llamó mi suerte”. Aparte de esto, la gran diferencia con el poema de Quevedo es que el de Carrillo está hecho a base de deícticos que apuntan hacia una imagen que se presenta ante los ojos de la imaginación del lector: "Mira esta rota entena....", "Mira la jarcia...., "Esta entena que ves...", "Aunque mudo [el barco destruido varado en tierra] te habla...". Las admoniciones y consejos acerca del porvenir surgen fundamentalmente del ejemplo presente, mientras que en el poema de Quevedo todo está proyectado hacia el futuro amenazador, salvo excepcionalmente el inicio de la cuarta estrofa: “¿No ves lo que te dicen esos leños...?”. Hay algunas semejanzas de detalle entre los dos poemas, como, por ejemplo, el uso del diminutivo "navecilla". En Carrillo, los restos de la embarcación se ven "vestir de ejemplo aquestas playas solas", mientras que en el otro poema están "vistiendo de escarmientos las arenas". En Quevedo es constante la contraposición entre el árbol en tierra y el árbol en el mar convertido en tablas y mástiles; la misma idea que, como ya hemos dicho, es un elemento frecuente en el tratamiento literario del tema de la navegación, aparece en Carrillo cuando dice: "Hija de noble selva, cual presume / tu nave altiva y fuerte, fue la mía". Aquí volvemos a encontrarnos con el precedente de Horacio, pues en estos versos se reflejan las palabras "silvae filia nobilis" de la oda XIV. Pero lo que sobre todo lleva a pensar en una relación entre los poemas de Quevedo y de Carrillo es que ambos están escritos en la

${ }^{16}$ Sobre la relación entre estos dos poemas de Quevedo y Carrillo, véase MARía José Tobar Quintanar, "La imitación de la elocutio clásica en la poesía de Quevedo", La Perinola, 3 (1999), 326-336. 
misma estrofa, la sexta rima, que aunque no sea insólita en la poesía española, no es tampoco demasiado frecuente. Sin embargo, es difícil dilucidar cuál de los dos pudo influir sobre el otro. El de Quevedo aparece por primera vez en lo que se ha llamado Segunda flor de poetas ilustres, que lleva fecha de 1611, el de Carrillo se encuentra en la edición impresa de sus poesías, que es del mismo año. Lo que sí podemos afirmar es que, frente a la vigorosa y contundente retórica de Quevedo, el poema de Carrillo presenta una factura un poco vacilante; el mismo hecho de que el significado amoroso que se quiere dar a la imagen de la navegación se base en una sola palabra produce un desequilibrio que hace que, en último término, el conjunto del poema resulte un tanto borroso y fluctuante.

Señalemos también dos sonetos de Francisco de Rioja, uno de los cuales, el que comienza "Este que ves, oh huésped, vasto pino" es, como ha señalado G. Chiappini ${ }^{17}$ una imitación del poema IV de Catulo, "Phaselus ille, quem videtis, hospites". El de Catulo es un poema votivo, en el que se consagra el barco, o quizá más probablemente una reproducción en pequeña escala, en señal de agradecimiento por una feliz navegación. Así pues carece totalmente del tono moralizante y desengañado propio de los demás poemas que estamos analizando, aunque en Rioja hay una frase, que no está en el modelo latino, acerca de la fugacidad de las cosas; el barco es hoy "útil sólo a la llama ya en el puerto". Algo parecido ocurre en un soneto de Quevedo, cuyas palabras están puestas en boca de la nave, y que comienza: "Mi madre tuve en ásperas montañas / si inútil con la edad soy seco leño"18. Por el contrario, el otro soneto de Rioja, el LII $^{19}$ se halla más cerca de nuestro tema. El poeta, como Horacio y Quevedo, se dirige a la embarcación, y, de la misma manera que Carrillo y Sotomayor, pone ante los ojos del lector los restos de un navío deshecho por múltiples viajes y tempestades: “¡Oh rotos leños y mojado lino, / horror a la ambición más lisonjera! / ¿Qué mal fundado error tu paz primera / en la selva turbó, robusto pino?”. El barco actual es presentado como ejemplo y advertencia de ambiciosos incautos, es decir, que es "horror a la ambición más lisonjera". En el segundo cuarteto, a la figura del árbol como emblema de quietud y seguridad se añade, como ya se ha anunciado en el primer verso, el de la planta de lino con que después se fabricarán las velas: "Y tú, atrevida hierba, que camino / a fábrica naval diste en la fiera / agua, ya por su injuria en la ribera / eres triste escarmiento al peregrino". La expresión "atrevida hierba" parece proceder del pasaje de Plinio

17 Francisco de Rioja, Poesía, ed. G. Chiappini, Fundación J. M. Lara, Sevilla, 2005 , p. 159.

18 Francisco de Quevedo, Obra poética, ed. J.M. Blecua, Castalia, Madrid, 1969-1981, núm. 249. En adelante, cito por esta edición e indico número.

19 F. DE Rioja, ed. cit. de B. López, p. 219. 
en el que, desarrollando el mismo tema de la condena de la navegación y hablando del lino dice que es espantoso que a una planta, que él califica de "tam gracili avena", la veamos tiempo después "ad summa audaciae pervenire" ${ }^{20}$. En los tercetos, Rioja expone el significado moral de la imagen: " $\mathrm{OH}$ mil veces dichoso el que igual cuenta / largas horas en ocio entre sus lares, / superior a vulgares opiniones, / que ni la suerte invidiará sedienta, / ni, inútil peso, temerá en los mares / escudriñar sus íntimas regiones!". La expresión "inútil peso" tiene una larga historia. Aparece en la Ilíada, cuando Aquiles se queja ante su madre de la muerte de Patroclo: "Ahora, puesto que no he de volver a la patria, ni he salvado a Patroclo ni a los muchos amigos que murieron a mano del divino Héctor, permanezco en las naves cual inútil peso de la tierra, etósion áchthos arúres" ${ }^{21}$. Sócrates cita la frase en su Apología (28 d), y luego Plutarco (Sobre la paz del alma, 2, 2) y también Luciano (Icaromenipo, 29). En la traducción latina de la Ilía$d a$ hecha por Helio Eobano Hesso (Basilea, 1540), la frase se traduce "telluris inutile pondus"; en la que se publicó, igualmente en Basilea, en 1583 con comentarios de Jean de Sponde, la versión dice: "inutile pondus terrae". Ambas expresiones aparecen en la poesía neolatina como una fórmula consagrada. Erasmo, en un epigrama satírico, dice: "Hic iacet Egmundus, telluris inutile pondus, / dilexit rabiem, non habeat requiem" ${ }^{22}$. Vincentius Opsopoeus, en su poema De arte iocandi, pregunta al hombre que no tiene amigos ni compañeros: "Dic mihi, quid fueris nisi pondus inutile terrae?"23. Nicolas Bourbon el Viejo increpa a los que, como son incapaces de nada bueno, critican las obras ajenas, llamándoles igualmente "pondus inutile terrae" ${ }^{24}$; Johannes Lucius aplica la frase a los perezosos: "Quisquis homo piger est, telluris inutile pondus / exstat"25. El dramaturgo William Gager, al hombre sin hijos: "indigne telluris inutile pondus / nascitur, ex quo non ortus et alter erit" ${ }^{26}$. John Milton, en uno de sus poemas latinos, lamenta que la muerte se lleve a los mejores, mientras que deja vivir tranquilos a los que, de acuerdo con la misma fórmula, son "pondus

${ }^{20}$ Plinio, Historia natural, ed. H. Rackham, Harvard University Press, 1979, XIX, I, 2-6.

${ }^{21}$ Homero, Ilíada, trad. L. Segalá, Juventud, Barcelona, 1972, XVIII, 104.

22 The poems of Desiderius Erasmus, ed. C. Reedijk, E.J. Brill, Leiden, 1956, p. 394.

${ }_{23}$ De arte bibendi libri tres, quibus adiunximus De arte iocandi libros quatuor, Frankfurt, 1578, lib. 3 (reproducido en línea: "Camena. Lateinische Texte der Frühen Neuzeit").

24 "Ferraria”, v. 343, consúltese en línea: "The Classics page at Ad Fontes Academy".

${ }_{25}$ Poematum tetras altera, Dresde, 1603, I, X, p. 17 (reproducido en el sitio en línea: "Camena. Lateinische Texte der Frühen Neuzeit").

26 The complete works, ed. D.F. Sutton, Garland, New York-London, 1994, t. 1, p. 11. 
inutile terrae" ${ }^{27}$. El autor la repite en inglés en su Aeropagitica: "many a man lives a burden to the earth" ${ }^{28}$. La expresión aparece en italiano en un soneto de G. Bruno puesto en boca de un ciego: "Qual talpa uscivi al mondo / e per esser di terra inutil pondo" 29 y en un poema de Luigi Tansillo, aunque aquí el "inútil peso" no oprima a la tierra, sino al propio yo: "Benché, a me stesso grave, inutil salma / io resti"30. Con un valor irónico, aparece igualmente en Marino, para hablar del amante exhausto, incapaz fisiológicamente de renovar sus asaltos amorosos: "Cosí mi giaccio inutil pondo apresso / a la mia ninfa amata" "31. También se encuentra, algo transformada, en el soneto 70 de Quevedo, cuando dice que alguien es "inútil número del suelo".

Semejanzas aún más evidentes con "Exhortación a una nave nueva" tiene la canción del Príncipe de Esquilache titulada "A la nave". El poema, escrito en estancias, está igualmente dirigido a la embarcación y los temas son los mismos que en Quevedo: el contraste entre el árbol y el navío, la advertencia acerca de los peligros del mar, el recuerdo del viento inofensivo en las ramas y terrible entre las olas encrespadas, la imagen de los nidos que las aves hicieron en las frondas del árbol, la condena de la codicia, el recuerdo de los votos de los marineros en la tempestad. Nos encontramos con dos poemas gemelos sobre cuya relación poco podremos decir, a la espera de que otros, mejor informados, puedan echar algo de luz sobre esta cuestión.

En adelante, copiaré el poema de Quevedo estrofa por estrofa, siguiendo la edición de Blecua, para ir añadiendo algunas anotaciones y comentarios. Sobre los problemas textuales que plantea esta composición, véase lo que dice María del Carmen Rocha de Sigler en Cinco silvas de Francisco de Quevedo ${ }^{32}$. Publico como apéndice el texto del poema del Príncipe de Esquilache, del que, por lo que sé, no hay edición moderna. La "Exhortación a una nave" empieza con las siguientes palabras:

¿Dónde vas, ignorante navecilla, que, olvidando que fuiste un tiempo haya, aborreces la arena de esta orilla, donde te vio con ramos esta playa,

5 y el mar también, que amenazarla osa, si no más rica, menos peligrosa?

27 The complete poetry, ed. J.T. Shawcross, Anchor, New York, 1971, p. 15.

28 Aeropagitica, en Prose writings, ed. K.M. Burton, Everyman's Library, LondonNew York, 1958, p. 150.

${ }^{29}$ Eroici furori, en Opere italiane, ed. G. Aquilecchia, Unione Tipografica Torinese, Torino, 2002, parte 2, diálogo 4, p. 717.

30 Il Canzoniere, ed. E. Pèrcopo, Liguori, Napoli, 1996, soneto 275.

31 Giovan Battista Marino, La lira, ed. M. Slawinski, Res, Torino, 2007, p. 306.

32 Universidad, Salamanca, 1994. 
[v. 1] La pregunta: “¿adónde vas...?”, con estas o parecidas palabras, tiene, tanto en la lengua literaria como en la coloquial, un valor de advertencia o admonición acerca del desastre o de la desgracia a que el interlocutor se está arriesgando: "Dove ne vai, -dicean-, dove, bricone? / Geta la spada, ché sei morto o preso"33; "Ove, misera, vai? Che sai s'anchora, / dice, vedrai più che mai bella e calda / quella che "l tuo destino hora t'asconde?"34; "Dove vai si per tempo, o rondinella?”35; "¿Adónde vas con alas tan ligeras?”36. La canción de Esquilache comienza de la misma manera: "¿Adónde vas, del viento acompañado, / a tan dudoso fin, errante pino...?”. Además, la interpelación es el primer rasgo, de los muchos que hay en el poema de Quevedo, de personalización de la nave. Después se dice de ella que es "ignorante", luego que "aborrece", etc.

[v. 2] Aparece aquí por primera vez la contraposición, que es uno de los ejes principales del poema, entre el árbol de cuya madera se ha fabricado el barco, emblema de seguridad y quietud, y el barco ya construido que se va a lanzar a un espacio lleno de dificultades y peligros. El barco "olvida que fue haya" pues parece que odia los lugares en donde, sin embargo, habitó plácidamente mucho tiempo.

Góngora fue censurado por el Abad de Rute ${ }^{37}$ por creer que la madera de haya se utiliza en la construcción de barcos, error que intentan disculpar Pellicer y Salcedo Coronel en sus comentarios. Vilanova observa el hecho curioso de que el único antecedente de Góngora en el uso de "haya" es una frase ("bien dichoso, si alguna haya / rota concede beses esta playa") de la canción a que hicimos referencia más arriba de Carrillo y Sotomayor,

cuyo cargo de cuatralbo de galeras le confería, sin duda alguna, una autoridad indiscutible en materias navales. Es muy posible que Carrillo aluda en este pasaje a un mástil o a una entena rota, pero como en el transcurso de la canción habla constantemente de una nave despedazada, es casi seguro que Góngora, siempre ansioso de novedad, le dio el sentido de 'alguna rota nave', tomando "haya" por "nave" en vez de pino, de uso tan corriente en la poesía clásica y renacentista. En fecha anterior a 1611, en que aparecen las Obras de

${ }^{33}$ Matteo Maria Boiardo, Orlando innamorato, ed. R. Bruscagli, Einaudi, Torino, 1995, I, XX, 12.

${ }^{34}$ Gian Giorgio Trissino, Rime, Biblioteca italiana, núm. 23, página en línea de la Università degli Studi di Roma "La Sapienza": www.bibliotecaitaliana.it.

${ }^{35}$ Luigi Groto, Rime, Venezia, 1610, II, p. 59.

${ }^{36}$ Lope De Vega, Rimas, ed. F. Pedraza, Universidad de Castilla-La Mancha, 1993-1994, t. 1, p. 251.

37 Véase la ed. de Jammes de las Soledades, p. 274. 
Carrillo, no he logrado encontrar ejemplo alguno de dicho uso por parte de Góngora ${ }^{38}$.

De acuerdo con eso, todos los usos posteriores de "haya” en Quevedo y en los otros poetas citados proceden de ese error de Góngora. Sin embargo, como señala Cristóbal Cuevas, ya fray Luis, en una de sus traducciones de Virgilio, pero apartándose del original latino, usa "haya" como sinécdoque de "barco"39.

[vv. 4-6] Esta playa te vio con ramas, y el mar, que amenaza a la playa con la fuerza de sus olas, te vio también, cuando tú no eras tan rica como ahora (pues no ibas cargada de mercancías), pero estabas menos sujeta al peligro. Ramos es aquí sinónimo de "ramas"; como dice el Dicc. Aut., "ramo es lo mismo que rama en su primera noción, si bien rigurosamente ramo se entiende el ya cortado del árbol". Comentando estos versos, dice Alfonso Rey: "Tal vez hay que estimar latinismo semántico peligrosa con el significado de "puesta en peligro', como ocurre a la nave que era, cuando árbol, 'si no más rica, menos peligrosa" "40. Quevedo emplea la palabra con este sentido en otros lugares: "El laurel que te abraza las dos sienes / llama al rayo que evita y peligrosas / y coronadas por igual las tienes" (núm. 104, vv. 12-14); "la vida peligrosa, / la muerte apresurada y belicosa" (núm. 145, vv. 310-311); "menos le vio galán que peligroso" (núm. 146, v. 60); "Mira la honra, peligrosa en este estado"11.

Si fiada en el aire, con él vuelas, y a las iras del piélago te arrojas, temo que desconozca por las velas

10 que fuiste tú la que movió con hojas: que es diferente ser estorbo al viento de servirle en la selva de instrumento.

[v. 7] "Si vuelas con el aire, que es el que empuja las velas del barco, te estás fiando de una cosa tan frágil y voluble como el viento". La hipérbole "volar" por "avanzar muy rápido" es frecuente en poesía hablando de los barcos: "pelagoque volans da vela patenti"42; "sive palmulis / opus fore volare sive linteo"43; hablando de la nave Argos,

38 Antonio Vilanova, Las fuentes y los temas del Polifemo de Góngora, Revista de Filología Española, Madrid, 1957, pp. 640-641. p. 430 .

39 Fray Luis de León, Poesías completas, ed. C. Cuevas, Castalia, Madrid, 2001,

40 Alfonso Rey, Quevedo y la poesía moral española, Castalia, Madrid, 1995, p. 140.

41 F. DE Quevedo, Doctrina moral, en Obras completas en prosa, ed. A. Rey, Castalia, Madrid, 2010, t. 4, p. 102. II, 41.

42 Virgilio, Geórgicas, ed. H.R. Fairclough, Harvard University Press, 1965,

43 Catulo, op. cit., IV. 
dice Ovidio: "Illa volat, ventus concava vela tenet" ${ }^{44}$. Pero esto se relaciona por otra parte con la idea de que las velas son como las alas del barco: "Suelen [los poetas] atribuir alas a los navíos o llamar así a las velas", dice Díaz de Rivas ${ }^{45}$, y Pellicer afirma: "Los antiguos quisieron que se pusiesen velas a los navíos a imitación de las alas de las aves, que del modo mismo que tendidas las alas vuelan, así las naves, tendidas las velas, navegan"46. Díaz de Rivas aduce los siguientes ejemplos: "Velorum pandimus alas" "47; "Nec te quod classis centenis remiget alis, / terreat" 48 ; "Scissis velorum debilis alis" 49 , aunque otras veces las alas no son las velas sino los remos ${ }^{50}$. También es frecuente el adjetivo "alado" con este uso en la poesía española: "al mar fiando, al viento, / no aromáticos leños, sino alados" "51; "Este en selva inconstante alado pino"52; "pues siendo alado pino / rastrero por el mar halló camino" 53 . Marino dice que Colón fue a América "con ali di lino e piè di legno"54; en otro lugar dice: "Vola la nave e, quasi augel de l'onde, / batte de' remi le spedite penne..."55.

[v. 8] Es algo consustancial a todas las culturas el hablar de la "ira", o de la "cólera" o de la "furia" del mar embravecido, al igual que de los vientos o de la tormenta. En cualquier caso, Horacio alude en el Beatus ille al "iratum mare" (v. 6), Ovidio dice "frangitur ira maris" 56 y Valerio Flaco, "Ira maris vastique placent discrimina ponti" ${ }^{57}$. Encontramos ejemplos, igualmente, en la poesía española: "Nunca del mar temiste / las iras procelosas"58; "una ciudad ocupada de las saladas iras del mar" 59 ; en otro poema, Quevedo habla de "las iras del mar

44 Heroidas, ed. H. Bornecque, Les Belles Lettres, Paris, 1928, 6, 66.

45 Eunice Joiner Gates, "Anotaciones a la canción de la toma de Larache por Pedro Díaz de Rivas", RFE, 44 (1961), p. 85.

${ }^{46}$ Lecciones solemnes a las obras de don Luis de Góngora, Madrid, 1630, col. 444.

47 Tomado de Virgilio, Eneida, ed. M. Rat, Garnier, Paris, 1960, III, 520.

48 Propercio, Obras, ed. H.E. Buttler, Harvard University Press, 1958, IV, 6 , 47-48.

49 Claudiano, "Panegírico al sexto consulado de Honorio", en Obras, ed. M. Platnauer, Harvard University Press, 1976, 137.

50 Odisea, XI, 109 ss.; LucRecIo, De rerum natura, eds. W.H.D. Rouse y M.F. Smith, Harvard University Press, 1982, VI, 743; Eneida, I, 301 y VI, 19.

${ }^{51}$ Luis de Góngora, Sonetos, ed. B. Ciplijauskaité, Castalia, Madrid, 1978, soneto 51 .

52 Juan de Vera Tassis, conde de Villamediana, Poesía impresa completa, ed.

J.F. Ruiz Casanova, Cátedra, Madrid, 1990, p. 289.

${ }^{53}$ E.M. DE Villegas, op. cit., p. 25.

${ }^{54}$ La Galeria, ed. M. Pieri, Liviana, Padua, 1979, p. 104.

${ }^{55}$ G.B. Marino, Adone, ed. G. Pozzi, Adelphi, Milano, 1988, XIX, 164, p. 1188.

56 Tristes, J. André, Paris, 1968, I, II, 108.

${ }_{57}$ Argonautica, ed. F. Caviglia, Rizzoli, Milano, 1999, I, 37.

${ }^{58}$ L. DE VeGA, La Dorotea, ed. E.S. Morby, Castalia, Madrid, 1968, p. 274.

${ }^{59}$ Sor Juana Inés de la Cruz, Inundación castálida, ed. G. Sabat de Rivers, Castalia, Madrid, 1982, p. 398. 
enfurecido" (núm. 98). El sujeto de "desconozca" es el aire, del v. 7. El aire, viendo las velas del barco, "no te reconocerá como aquel árbol cuyas hojas antaño movía”.

[vv. 11-12] Es diferente ser estorbo al viento en las velas que servirle de instrumento en el bosque, según lo cual los dedos del viento tañen el instrumento musical que es la copa del árbol. El tema de las velas como obstáculo que se le opone al viento, aparece en otros escritores: "e frenar sotto'l giogo Austro nemboso / osa del curvo lin" ${ }^{60}$; "E vide al volo audace / orea spiegar i lini / i dianzi a' fiati suoi caduti pini" ${ }^{61}$. En un poema de Bartolomé L. de Argensola, el poeta se dirige al lino y dice: "cuando navales fábricas compones / y, al viento opuesta, a descubrir regiones / vuelas"62. El Príncipe de Esquilache trata varias veces el tema: "topando el viento en medio del camino / montañas blancas de cambiante lino"63; "el soplo más soberbio y más molesto / sirvió a la industria del osado lino" (ibid., p. 332,); "romper le vio con movimiento leve / las crespas ondas, sin dejar camino, / y al libre viento que sus tablas mueve / prender la industria en cárceles de lino" (ibid., p. 346).

¿Qué codicia te da reino inconstante, siendo mejor ser árbol que madero,

15 y dar sombra en el monte al caminante, que escarmiento en el agua al marinero? Mira que a cuantas olas hoy te entregas les das sobre ti imperio si navegas.

[v. 13] "reino inconstante": el mar. "Inconstante", aplicado al mar, es un epíteto común en la poesía de la época: "La que de árbol sin llover, / la que del mar inconstante..."64; "Si el industrioso mercader se atreve / al inconstante mar"65; "¡Oh alma mía, tú que andas... zozobrando en el inconstante mar del mundo!"66; "el mar siempre inconstante” (Quevedo, núm. 115). L. L. de Argensola dice: “¡Oh tú, que a los peligros e inconstancia / del mar te obligas...!"67.

60 Angelo Grillo, Rime, Venezia, 1599, VI.

61 G.B. Marino, La lira, t. 1, p. 371.

62 Rimas, ed.J.M. Blecua, Clásicos Castellanos, Madrid, 1974, t. 1, p. 169.

63 Nápoles recuperada, ed. cit., p. 330.

64 Lope de VEGA, El villano en su rincón, ed. Zamora Vicente, Espasa Calpe, Madrid, 1963, p. 47, vv. 1134-1135.

65 B. De Balbuena, Poesía lírica, ed. M. Barchino, Diputación Provincial de Ciudad Real, 2000, p. 282.

66 Baltasar Grací́n, El comulgatorio, eds. M. Batllori et al., Larumbe, Zaragoza, 2003, p. 48.

${ }^{67}$ Rimas, ed.J.M. Blecua, Clásicos Castellanos, Madrid, 1972, p. 57. 
[v. 14]) La palabra "madero" es muy frecuente en poesía como metonimia por "barco": "Y al tiempo que pasando va el madero, / con remos o con velas sustentado" 68 ; "Gobierna entre las ondas su madero / Telón, un griego, que chalupa alguna / no vio jamás tan diestro marinero"69; "iMalhaya aquel que primero / pinos en el mar sembró, / y el que sus rumbos midió / con quebradizo madero"70. Pero aquí, "madero", se opone, además, a "árbol" como lo que está muerto frente a lo que está vivo.

[vv. 15-16] La contraposición entre el árbol que da sombra al caminante y el barco que hará peligrar al marinero aparece, como observa Candelas Colodrón ${ }^{71}$, en el soneto de Rioja que ya hemos visto: "Este que ves, oh huésped, vasto pino, / útil sólo a la llama, ya en el puerto, / selva frondosa un tiempo, en descubierto / cielo dio amiga sombra al peregrino". La misma idea aparece en otro poema de Quevedo, puesto en boca del barco, que dice: "mi sombra fue regalo a más de un sueño, / supliendo al jornalero las cabañas" (núm. 249), y la encontramos igualmente en los vv. 15-18 de la canción del Príncipe de Esquilache que transcribimos en el Apéndice.

La idea de "escarmentar" en relación con el tema del naufragio tanto real como simbólico aparece en Diego Hurtado de Mendoza: "fuera del inconveniente, / colgar las mojadas prendas, / donde las veas y entiendas / que hay alguno que escarmiente"72. En el soneto citado de Rioja ${ }^{73}$ se dice que esos vestigios son "triste escarmiento al peregrino"; en otro de sus poemas los restos del naufragio serán "escarmiento al atrevido" (p. 189). Cf. también: "Su ruina trofeo de elementos / será, cuanto escarmiento a navegantes"74; "Por ti, de las infieles / ondas y su camino / sacar pudo escarmiento el más osado"75; "Los naufragios, vistos desde la arena, conmueven el ánimo, pero no el escarmiento"76; "Sea en las fieras ondas que navego / norte seguro, pues, el desengaño, / que el escarmiento agradecido adora" "; "¿Cuándo ya para escarmientos / derrotados de altivez

${ }^{68}$ Luis Barahona de Soto, Las lágrimas de Angélica, ed. J. Lara Garrido, Cátedra, Madrid, 1981, p. 436.

${ }^{69}$ J. DE JÁuREGUi, op. cit., t. 1, p. 83.

70 Tirso de Molina (atribuida a), El burlador de Sevilla, ed. A. Rodríguez, Cátedra, Madrid, 1990, p. 197.

${ }^{71}$ Las silvas de Quevedo, Universidad, Vigo, 1997, p. 135.

72 Poesía completa, ed. J.I. Díez Fernández, Planeta, Barcelona, 1989, p. 137.

73 “¡Oh rotos leños y mojado lino....", p. 219.

${ }^{74}$ Conde de Villamediana, Poesía impresa completa, p. 337.

75 J. DE JÁuregui, op. cit., t. 1, p. 40.

76 Diego Sanvedra Fajardo, Empresas políticas, ed. F.J. Díaz de Revenga, Planeta, Barcelona, 1988, p. 197.

77 Gabriel Bocángel, La lira de las musas, ed. T.J. Dadson, Cátedra, Madrid, 1985, p. 153. 
/ en la playa de los años / perdido anciano bajel?"78 "El que fiare sus velas / a tiempos de tan mal tiempo / saldrá de la mar a fuerza / de remos y de escarmientos"79; "porque quiso su destino / que, en la seguridad de alado pino, / a los mortales sirva de escarmiento" ${ }^{80}$. En otro poema dice Quevedo, dirigiéndose a los restos del navío: "premiad con mi escarmiento mis congojas" (núm. 7).

¿No ves lo que te dicen esos leños,

20 vistiendo de escarmientos las arenas, y aun en ellas los huesos de sus dueños, que muertos alcanzaron tierra apenas? ¿Por qué truecas las aves en pilotos y el canto de ellas en sus roncos votos?

[vv. 19-20] Como ya hemos dicho, nos encontramos aquí con el único momento del poema en que se pone ante los ojos del interlocutor ficticio una imagen presente.

Los leños "visten de escarmientos las arenas", al igual que en el poema de Carrillo y Sotomayor los vemos "vestir de ejemplo aquestas playas solas" 81 . La palabra "leño" se usa muchas veces como sinónimo de "barco", tanto en la literatura española como, desde mucho antes, en la italiana: "misi me per l'alto mare aperto / sol con un legno"82; "quasi senza governo e senza antenna / legno in mar"83; "mil olas a porfía / hunden en el abismo un desarmado / leño de vela y remo" 84 ; "Mas ya venciendo el ímpetu marino / surcan armados leños el Tirreno"85; "Tiflis el primer leño mal seguro / condujo, muchos luego Palinuro" ${ }^{\circ 6}$. Sobre este uso de la palabra, véase Lapesa y E. de Bustos $^{87}$. Aquí la palabra es ambivalente, pues se puede entender que en la playa hay restos de varios barcos naufragados o bien que hay trozos de un barco que se ha estrellado en la orilla, con lo que "leños"

78 A. Hurtado de Mendoza, Obras poéticas, ed. R. Benítez Claros, RAE, Madrid, 1947, t. 2, p. 24.

${ }^{79}$ Ibid., p. 244.

${ }^{80}$ Juan de Moncayo, Rimas, ed. A. Egido, Espasa-Calpe, Madrid, 1976, p. 81.

81 Poesías completas, ed. D. Alonso, Signo, Madrid, 1936, p. 104.

82 Dante Alighieri, La divina commedia, ed. N. Sapegno, La Nuova Italia, Firenze, 1973, Inferno, XXVI, 100-101.

83 Petrarca, Canzoniere, ed. P. Cudini, Garzanti, Milano, 1986, CLXXVII.

${ }^{84}$ Fray Luis de León, Poesía, ed. Ramajo Caño, Círculo de Lectores, Barcelona, 2006, p. 143.

${ }_{85}$ B.L. De Argensola, op. cit., t. 2, p. 107.

${ }^{86}$ L. DE Góngora, Soledades, ed. cit., t. 1, vv. 397-398.

87 Rafael Lapesa, "El cultismo en la poesía de fray Luis de León", en Poetas y prosistas de ayer y de hoy, Gredos, Madrid, 1977, pp. 116-117, y Eugenio de Bustos, "Algunas observaciones semiológicas y semánticas en torno a Fray Luis de León", Academia Literaria Renacentista, t. 1: Fray Luis de León, Universidad, Salamanca, 1981, pp. 135-136 y 139-142. 
estaría empleado en su sentido propio de "trozos de madera", como en otro poema de Quevedo en que se dice de una nave que, "dando en un bajío, / sus leños desató su mesmo brío” (núm. 279, vv. 14-15).

En el v. 16 aparecía la palabra "escarmiento", una de las predilectas del vocabulario de Quevedo, en su uso normal, según el cual el naufragio o los restos del barco naufragado sirven de "escarmiento" o advertencia al que piensa hacerse a la mar. A partir de ahí, Quevedo crea la metonimia según la cual el "escarmiento" se identifica, sin más, con los restos del barco naufragado. Así en el soneto que comienza: "Más escarmientos dan al Ponto fiero, / si atiendes, la bonanza y el olvido..." (núm. 57), es decir, "más naufragios produce la bonanza que la tempestad"; o cuando se dice de una nave que "en maligno escollo, inadvertida, / de escarmientos, la playa procelosa, / infamó, en mil naufragios dividida" (núm. 112), o de otra cuyos restos "de escarmientos todo el mar poblaron" (núm. 279, v. 15). Igualmente, aquí "escarmientos" son los restos del barco esparcidos por la playa.

[v. 21] La imagen de una playa cubierta de huesos de náufragos (o de marineros devorados por las sirenas, o de muertos por otro motivo) aparece en la poesía latina, aunque siempre con la característica, que aquí Quevedo omite, de que los huesos son blancos o que "blanquean" la playa: "Iamque adeo scopulos Sirenum advecta subibat, / difficilis quondam multorumque ossibus albos"88. Según Ovidio, ante la caverna de Caco, "humanis ossibus albet humus" ${ }^{89}$. Escenas semejantes se encuentran también en textos históricos: "medio campi albentia ossa, ut fugerant, ut restiterant, disiecta vel aggerata"90; "Humatis denique, pro locorum et temporis ratione, honoratis quibusdam inter defunctos, reliqua peremptorum corpora dirae volucres comsumpserunt, assuetae illo tempore cadaveribus pasci, ut indicant nunc usque albentes ossibus campi"91. La imagen aparece con frecuencia en la poesía del Renacimiento y el Barroco: "e i campi biancheggiare, / prima vaghi e depinti, / carchi or de l'ossa de' miseri estinti"92; "di far, che di nemiche ossa coperti, / divengan bianchi campi ampi et aperti" 93; "Questi... / poggi e monti d'ossa... / che... / biancheggian su queste straniere arene"94; "Veo los hue-

88 Eneida, V, 864-865.

89 Fastos, ed. J.G. Frazer, Harvard University Press, 1976, I, 558.

90 TAcito, Anales, ed. J. Jackson, Harvard University Press, 1962, I, 61.

91 Ammiano Marcellino, Le storie, ed. A. Selem, Unione Tipografico-Editrice Torinese, Torino, 1973, lib. XXXI, 7, 16.

${ }^{92}$ B. TAsso, Salmi, Rime, Ode, 18, consultado en la página en línea de la Biblioteca Italiana de la Università degli Studi di Roma "La Sapienza": www.bibliotecaitaliana.it.

93 B. Tasso, Rime, ed. cit., II, 12.

94 L. TANsillo, op. cit., soneto 219. 
sos blanquear, y siento / el triste son de la engañada gente" 95 ; "No le bastó después a este elemento... / infamar blanqueando sus arenas / con tantas del primer atrevimiento / señas" 96 ; recuérdese, también de Góngora, el soneto 78: "he visto blanqueando las arenas / de tantos nunca sepultados huesos" ${ }^{97}$, que es a su vez imitación de Torquato Tasso: "veggio... biancheggiar le arene d'ossa insepolte"98; véase igualmente: "Tras esto, ¿no miráis los compañeros / ya por los arrecifes blanqueando?" 99 ; “quedando... sus arenas / de rotas mallas y de huesos llenas"100; "Quanto vaglia il mio braccio e quanto possa / faranne quest'arena eterna fede, / laqual di sangue per gran tratto e d'ossa / rosseggiar tutta e biancheggiar si vede"101; "Hablen los nunca sepultados huesos / que en las playas blanquean, / de tantos que por falta de sustento / al mar rindieron el vital aliento"102; "Nunca en el alto Péloro, cubierto / de blancos huesos, voz más regalada / Parténope entonó..."103; "El Péloro se llama esotra punta / que ya un tiempo llamarse Italia pudo / y en blancos huesos dio y gente difunta / nevada de Leucosa el canto agudo" (ibid., p. 305); "Es fama que otro tiempo dieron, canas / de blancos huesos de hombres, sus riberas..." (ibid., p. 387); "quedando Faraón hundido, / de cuyas gentes aún se ven, espesos, / en sus riberas blanquear los huesos"104. Quevedo dice en otro poema: "golfo navegaré que, encanecido / de huesos, no de espumas..." (núm. 84).

\section{[v. 22] "que llegaron a tierra muertos".}

[vv. 23-24] Continuando con el contraste entre el árbol y el navío, se habla de trocar las aves que se posan en las ramas del árbol por los pilotos de los barcos, lo cual sirve para crear el nuevo contraste entre el canto agradable de los pájaros y los gritos roncos de los marineros aterrorizados en medio de la tempestad. La idea de los "votos de los marineros en la tormenta” es un lugar común de la poesía lati-

95 Fernando de Herrera, Sonetos, ed. R. García González, Biblioteca Virtual Miguel de Cervantes, Alicante, 2005, soneto 103, vv. 9-10.

96 L. DE Góngora, Soledades, ed. cit., t. 1, vv. 435-410.

97 Sonetos, ed. cit., p. 143.

98 Rime, en Opere, ed. B. Maier, Rizzoli, Milano, 1963, II, 4.

99 Lope de Vega, La Dragontea, ed. A. Sánchez Jiménez, Cátedra, Madrid, 2007, p. 521 .

100 Lope De VegA, La hermosura de Angélica, ed. M. Trambaioli, Universidad de Navarra, Pamplona, 2005, p. 204.

101 Marino, Adone, ed. cit., XIX, est. 178, p. 1191.

102 F. DE Rioja, Poesía, ed. cit. de B. López, p. 175.

103 B. De Balbuena, El Bernardo, en Poemas épicos, Atlas, Madrid, 1945, BAE, 17 , p. 225 .

104 Luis Martín de la Plaza, Poesías completas, ed. J.M. Morata Pérez, Diputación Provincial de Málaga, 1995, p. 243. 
na: "Votaque servati solvent in litore nautae"105; "Non est meum, si mugiat Africis / malus procellis, ad miseras preces / decurrere et votis pacisci"106; "Ipse gubernator, tollens ad sidera palmas, / Exposcit votis, inmemor artis, opem"107; "In vota miseros ultimos cogit timor" ${ }^{108}$. También aparece el tema en el epigrama 12 del libro XIII de la Antología griega. El tópico es muy frecuente en la literatura posterior: "Dolor: Magno naufragio vexatus sum. Ratio: Dicidisti Deum orare, votaque facere, et pascisci multa, quorum etsi metus causa fuit, tu tamen agnosce fidem terre redditus. Non impune Deus luditur: odit ille fidefragos"109; "Nulla salus, spes nulla viris; in vota precesque / vertuntur"110; "E'l mar già molto grosso è divenuto; / onde ciascun per tema de la morte / facendo voti a Dio dimanda aiuto"111, "Or, se mi mostra la mia carta il vero, / non è lontano a discoprirsi il porto; / sì che nel lito i voti scioglier spero / a chi nel mar per tanta via m'ha scorto"112, "piangeano, i marinari, e facean voti"113; "Ya comenzamos a enjugar la ropa, / y a encarecer del mar la brava guerra, / y a recontar los votos que hezimos"114; "Las galeras... / en fin aportan... / a Barcelona; do cumplidos / los votos ofrecidos"115; "quién hace voto expreso, quién promesa"116; "Ma io pur erro in tempestose piagge, / né veggio ancora ove ricovri e scampi, / e co' miei voti il ciel placo ed adoro"117; "cumpla los votos quien con rostro muerto / hizo promesas en el mar airado"118; “...después de haberlo en voto

105 Virgilio, Geórgicas, ed. cit., 1965, I, 436.

106 Horacio, Odas, Épodos, ed. C.E. Bennett, Harvard University Press, 1964, III; $29,57-59$.

107 Ovidio, Tristes, ed. cit., I, XI, 21-22.

108 SÉnecA, Agamenón, en Tragedies, ed. F.J. Miller, Harvard University Press, 1978 , t. 2, v. 510 .

109 Petrarca, De remediis utriusque fortune, ed. C. Carraud, J. Millon, Grenoble, 2002, t. 2, 54 .

110 Giovanni Pontano, Poesie latine, ed. L. Monti Sabia, Einaudi, Torino, 1977, p. 454 .

111 BoIARdo, Orlando innamorato, ed. cit., II, XXVII, 43, p. 1002.

112 Ludovico Ariosto, Orlando furioso, ed. M. Turchi, Garzanti, Milano, 1978, XLVI, I, p. 1268.

113 Gian Giorgio Trissino, L'Italia liberata dai Goti, canto III, consultado en la página en línea de la Biblioteca Italiana de la Università degli Studi di Roma "La Sapienza": www.bibliotecaitaliana.it.

114 Juan Boscán, Obras, ed. C. Clavería, PPU, Barcelona, 1991, p. 353; véase también p. 368.

115 Garcilaso de la Vega, Poesías castellanas completas, ed. E.L. Rivers, Castalia, Madrid, 1969, égloga II, vv. 1695-1699, p. 216.

116 Alonso de Ercilla, La Araucana, ed. I. Lerner, Cátedra, Madrid, 1993, XVI, 32, p. 477.

117 TAsso, Rime, ed. cit., núm. 890, p. 821.

118 Miguel de Cervantes, La Galatea, eds. F. Estrada y M.T. López GarcíaBerdoy, Cátedra, Madrid, 1995, p. 521. 
así ofrecido / cuando salí del bravo mar a nado”119; “¿O si será más proprio que el piloto, / cuando luchare con el Euro y Noto, / prometa ronco visitar tu templo?"120; "...roncas voces y votos / llevando de los míseros pilotos” (ibid., p. 166); "Allí sí que los votos y promesas / dichas tan bien, pero tan mal cumplidas, / salen del alma"121; "Traes, como suele rico navegante, / lo que votó en mitad de sus fatigas"122; "Ya mi aliento me da que al viaje ignoto / de mi barca halle puerto y cumpla el voto"123; "Del impío marinero, ya devoto, / envuelto en voces sube el sentimiento / al cielo, que desprecia, malcontento, / del pasajero humilde el casto voto"124; "El marinero con los remos rotos / ofrece al cielo duplicados votos"125; "Ya la culpable dilación se atreve / al sacro voto, religioso y pío, / que se ofreció con miedo en la tormenta / y en tierra agora sin cumplir se cuenta"126; "Y ya que mira con dolor y espanto / casi rota la nave, humilde voto, / Virgen, te ofrece"127; "te obligas / a fatigar con ruegos los oídos, / tan bien votados cuanto mal cumplidos"128; "Lloran los marineros / confirmando sus lágrimas sus votos" ${ }^{29}$; "Miro el inquieto mar como el piloto / que corriendo fortuna en golfo incierto, / a pesar de las ondas toma puerto, / debido a los afectos de su voto"130; "Vivo, a tierra salí; besé la arena, / y los despojos de la ondosa furia / pagué, cumpliendo el voto, al sacro templo"131. Véase también Quevedo: "¿Qué me dictó de votos la tormenta!" (núm. 32); "y por fuerza piadoso, / a cuantos votos dedicaba a gritos, / previno en la bonanza / otros tantos delitos" (núm. 145, vv. 100-103).

[v. 24] "roncos": Quevedo emplea en otros lugares este adjetivo, tratando el mismo tema: "no siempre el Ponto en sus orillas roto / ejercita los roncos marineros" (núm. 66); “¿No ves la turba ronca y amarilla

119 Cristóbal de Virués, Historia del Monserrate, Atlas, Madrid, 1945, en BAE, t. 17 , p. 557.

${ }^{120}$ Lupercio Leonardo de Argensola, Rimas, ed. cit., p. 140.

${ }^{121}$ Lope, La Dragontea, ed. cit., p. 278.

122 José de Valdivielso, Vida de San Josef, en Poemas épicos, Atlas, Madrid, 1948, en $B A E$, t. 29, p. 208.

${ }^{123}$ B. de Balbuena, El Bernardo, ed. cit., p. 388.

${ }^{124}$ Francisco de Medrano, Poesía, ed. D. Alonso, Cátedra, Madrid, 1988, p. 209.

125 Alonso de Acevedo, De la creación del mundo, Atlas, Madrid, 1948, en BAE, t. 29 , p. 266.

${ }_{126}$ Príncipe de Esquilache, Nápoles recuperada, ed. cit., p. 293.

127 L.M. DE LA Plaza, op. cit., p. 143.

${ }^{128}$ P. Espinosa, op. cit., p. 145.

129 Luis Carrillo de Sotomayor, op. cit., p. 132.

130 Conde de Villamediana, Poesía impresa completa, p. 333; véanse también pp. 389 y 529 , v. 58 .

131 Juan de Arguijo, Obra poética, ed. S.B. Vranich, Castalia, Madrid, 1971, p. 157. 
/ desconfiar del arte y del piloto...?" (núm. 123). Encuentro el mismo epíteto en los versos ya citados de Lupercio L. de Argensola: “ $¿ \mathrm{O}$ si será más propio que el piloto, / cuando luchare con el Euro y Noto, / prometa ronco visitar tu templo?"132 y "roncas voces y votos / llevando de los míseros pilotos" (ibid., p. 166). Luis Martín Plaza, en una traducción de Horacio (Odas, II, 16, pero el adjetivo no figura en el original) dice, hablando del piloto en la tempestad, que "los oídos fatiga / con ronca voz"133.

25 ¡Oh qué de miedos te apareja airado con su espada Orión, y en sus centellas más veces te dará el cielo nublado temores, que no luz, con las estrellas! Aprenderás a arrepentirte en vano

30 hecha juego del mar furioso y cano.

[v. 25] "Qué de miedos te apareja”: “cuántas situaciones terribles te tiene preparadas Orión con su espada”.

[v. 26] Orión era un gigante de la mitología que fue convertido en constelación; tres estrellas en ella forman la espada del personaje. Por eso, Ovidio alude a "nitidumque Orionis ensem"134 y le llama "ensifer Orion"135, mientras que Virgilio dice: "armatumque auro circumspicit Oriona"136. Es una constelación invernal, asociada con la lluvia y el mal tiempo ${ }^{137}$. Propercio habla de "aquosus Orion"138. Véase también: "Orione armato / spezza a' tristi nocchier governi e sarte"139; "Temerá o marinheiro a Orionte"140; "Amaina, dice, amaina, cuando mira / que se arma el Orión de rayos de ira"141. A veces se identifica poéticamente a la espada de Orión con las amenazas de tempestad: "Latus ense quieto / securum, magnus quanto mucrone minatur / noctibus hibernis et sidera terret Orion"142; "né perch' Orion fiero / insin dal cielo con la spada in mano / conturbi il mare insano"143;

132 Op. cit., p. 140.

133 Op. cit., p. 202.

134 Metamorfosis, XIII, 294.

135 Fastos, IV, 388.

136 Eneida, III, 517.

137 Así en Eneida, I, 535 y IV, 52; Horacio, Épodos, X, 10, y Ovidio, Fastos, IV, 388.

138 Obras, II, XVI, 51.

139 Petrarca, Canzoniere, XLI, p. 59.

140 Luis de Camõens, Lírica, eds. J.M. Rodrigues y A. López Vieira, Coimbra, 1932, ode XII, p. 276.

141 Lope DE VegA, "La Circe”, Obras poéticas, ed.J.M. Blecua, Planeta, Barcelona, 1983, p. 970.

142 Estacio, Silvae, ed. H. Frère, Les Belles Lettres, Paris, 1944, t. 1, 1, vv. 43-45.

143 B. Tasso, Ode, ed. cit., 44. 
"del Orión severo / la espada en agua de la mar teñida"144; "Entumécese el piélago, y el cielo / así del Orión juega la espada..." "45; "la qual [espada] tra i foschi orror rassembra quella / che vibra in ciel la procellosa stella"146. Para hablar de una tempestad fingida por arte de magia, dice Lope: "la espada de Orión se está en su vaina, / que son barquillas y borrasca hechiza"147.

[v. 26] "centellas": en el lenguaje del Siglo de Oro podía significar, como ocurre en este caso, "relámpagos". Cf.: "los sinos do se esconde el viento helado / y a do el Cilenio esparce sus centellas"148.

[v. 29] "aprenderás a arrepentirte en vano": "sabrás lo que es arrepentirse de algo cuando ya no tiene remedio".

[v. 30] "juego": juguete.

[v. 30] "furioso" y "cano" son epítetos canónicos del mar. Cf.: "Tirsis, la nave del cuitado Iolas / hecha tablas, la vuelca el mar furioso"149; "vertiendo en el revuelto mar furioso / de bautizada sangre un río espumoso"150; "Arrojé la capa al toro, / y al mar furioso la hacienda"151. En latín es frecuente el adjetivo "canus" para calificar, entre otras cosas, a la espuma del mar o de los ríos: "sed fluctu spumabant caerula cano"152. De ahí procede su uso en la poesía castellana: "iba de espuma cana el agua llena"153; "y este interpuesto mar con más creciente / teñido en roja sangre el color cano"154; "entre dos mirtos que, de espuma canos..."155. Lo que ocurre es que mientras en latín "canus" se aplicaba con igual propiedad a la espuma del mar que a los cabellos blancos, en castellano se debió de sentir siempre como metáfora, según la cual la espuma se comparaba con el color de los cabellos. Ésta es la que da el Dicc. Aut. como primera acepción de "cano",

${ }^{144}$ Lope, Rimas, ed. cit., t. 1, núm. 27, p. 245.

${ }^{145}$ Lope, La Dragontea, ed. cit., p. 248.

146 Marino, Adone, XIV, 131, p. 827.

147 La hermosura de Angélica, ed. cit., p. 478.

148 Fray Luis de León, Poesía, ed. cit., p. 234.

149 Francisco de la Torre, Poesía completa, ed. M.L. Cerrón Puga, Castalia, Madrid, 1984, p. 165.

150 A. DE Ercilla, La Araucana, ed. cit., XXI.

${ }^{151}$ Lope DE VeGA, El peregrino en su patria, ed.J.B. Avalle-Arce, Castalia, Madrid, 1973, p. 457.

152 Eneida, VIII, v. 672.

${ }^{153}$ Garcilaso, Obra poética, ed. B. Morros, Crítica, Barcelona, 1995, égloga II, v. 1637.

154 A. De Ercilla, La Araucana, XXIV, 36, p. 670.

155 Góngora, Polifemo, ed. D. Alonso, Gredos, Madrid, 1967, v. 211. 
añadiendo después: "metafóricamente lo usan los poetas para pintar la blancura de muchas cosas".

¡Qué pesos te previene tan extraños

la codicia del bárbaro avariento!

¡Cuánto sudor te queda en largos años!

¡Cuánto que obedecer al agua y viento!

35 Y al fin te verá tal la tierra luego, que te desprecie por sustento el fuego.

[v. 31] "extraños" parece usado aquí en el sentido de "singular, extraordinario” (Dicc. Aut.); o quizá, más exactamente, en este contexto, con el significado de "excesivos".

[v. 32] Es tradicional la idea de que la navegación es producto de la codicia y de la avidez de metales preciosos. Pedro Díez de Rivas, en sus anotaciones a la "Canción de la toma de Larache" de Góngora, comentando el verso "piloto el interés sus cables ata", dice: "Es cosa común a los autores decir que la cudicia fue causa de intentar las navegaciones... De aquí nacieron muchas odas y canciones de poetas vulgares a la cudicia de los navegantes"156. Compárese con "Quaerat avarus opes et, quae lassarit arando, / aequora periuro naufragus ore bibat"157; "Natura insidians pontum substravit avarus"158; "et inmensa multitudo aperto, quodcumque est, mari hospitalique litorum omnium adpulsu navigat, sed lucri, non scientiae, gratia"159; "Pues esta [la nave] fue inventada por la codicia de lucro" (Sabiduría, 14, 2) ${ }^{160}$. Tasso habla de "naviganti avari"161 y del que busca nuevas tierras "vago di gloria e d'oro" (ibid., núm. 956, p. 871). Celio Magno dice: "Ma tu, sol d'ogni vizio / radice e fonte d'ogni infame essempio, / cieca avarizia, tu da pria formasti / l'uman tormento, e tu la via mostrasti / d'accrescer anco il mar col nostro pianto"162. Compárese con "Tú, Cudicia, tú, pues, de las profundas, / estigias aguas torpe marinero, / cuantos abre sepulcros el mar fiero / a tus huesos, desdeñas"163; "Oro, tirano altivo... / por ti se dedican tan-

156 JoIner Gates, art. cit., p. 86.

157 Ovidio, Amores, ed. H. Bornecque, Les Belles Lettres, Paris, 1968, II, X, vv. 34-35.

158 Propercio, op. cit., III, 7, 37.

${ }^{159}$ Plinio, op. cit., II, 45.

160 Cf. también Antología griega, IX, 29.

161 Rime, núm. 485 , p. 506.

162 Rime, 8, consultado en la página en línea de la Biblioteca Italiana de la Università degli Studi di Roma "La Sapienza": www.bibliotecaitaliana.it.

163 Góngora, Soledades, ed. cit., t. 1, vv. 443-446. 
tas vidas... / al sulco incierto de nadantes proras, / y al furor de las ondas bramadoras" ${ }^{164}$.

[v. 33] El "sudor" es una metonimia ya lexicalizada por "trabajos, esfuerzos"; pero en este caso es también una metáfora personificadora, entre las muchas que hay en el poema, pues "sudar" sólo es aplicable a personas o animales. Puede haber aquí un recuerdo del épodo $\mathrm{X}$ de Horacio, donde, pronosticando una accidentada travesía, dice: "o quantus instat navitis sudor tuis" (v. 15).

[v. 36] Rioja hablando del barco viejo decía que es "útil sólo a la llama ya en el puerto"165; Quevedo dice que hasta el fuego le despreciará por inútil.

Tú, cuando mucho, a robos de un milano en tiernos pollos hecha, peregrina y esclava de un pirata o de un tirano, te harás del rayo de Sicilia dina; y más presto que piensas, si te alejas, el puerto buscarás, que ahora dejas.

[vv. 37-38] "Tú que, a lo más, cuando eras árbol, estabas acostumbrada [«hecha»] a los robos de un milano, es decir, a que el milano robara los polluelos de un nido que se hallaba en tus ramas". Creo que se trata de una asociación puramente casual, pero es curioso recordar que el milano es un elemento canónico de la iconografía marítima. C. Ripa dice que la navegación debe ser simbolizada por una mujer que, entre otras cosas, "mira atentamente en dirección a un milano que vuela por los aires", porque "Plinio, en su Historia Natural... dice que los antiguos descubrieron las ventajas de dotar a la nave de un timón a partir de la observación del vuelo de este pájaro"166. Cf. Plinio y Polidoro Virgilio ${ }^{167}$.

[v. 38] "peregrina": la palabra resulta ambivalente: o bien puede ser que "peregrina" signifique que, lo que ahora es nave, cuando era árbol fue arrancado de su lugar y transportado hasta las aguas, o bien que lo que antes estaba fijo y enraizado ahora es "peregrino", es decir, que se mueve por sobre las ondas del mar. Un ejemplo del primer sentido posible lo encontramos en otro poema de Quevedo: "Diste crédito a un pino, / a quien, del ocio rudo, avara mano / tra-

${ }^{164}$ J. DE JÁuregui, op. cit., p. 38.

165 Poesía, ed. cit. de B. López, p. 159.

166 Iconología, trad. J. y Y. Barja, Akal, Madrid, 2002, II, p. 122.

167 Plinio, op. cit., lib. X, XII, 28 y Polidoro Virgilio, De inventoribus rerum, ed. y trad. B.P. Copenhaver, Harvard University Press, 2002, p. 471. 
jo del monte al agua, peregrino" (núm. 136, vv. 1-3); del segundo lo encontramos cuando habla de la "peregrina diligencia" de los marineros (núm. 142, v. 70) o cuando se dice de la esposa del Cantar de los cantares que va "sola y peregrina" (núm. 198, v. 92).

[v. 39] Los robos del milano se contraponen a los del pirata que acaso será dueño de la nave.

[v. 40] "Te harás digna del rayo", es decir, "merecerás el castigo de Júpiter". "De Sicilia" funciona como un epíteto, pues según la mitología, los rayos eran fabricados por Vulcano, cuya fragua se hallaba en Sicilia, bajo el Etna. "Es cosa muy común en los poetas decir que el Etna es oficina de Vulcano"168. Véase Eneida ${ }^{169}$.

¡Oh qué de veces, rota en las honduras del alto mar, ajena de firmeza,

45 has de echar menos tus raíces duras y del monte la rústica aspereza! Y con la lluvia te verás de suerte que en lo que te dio vida temas muerte.

[v. 44] "alto" es un latinismo frecuente en la poesía áurea con el significado de "hondo", pero a la vez hay una antítesis entre "alto" y "honduras".

[v. 45] "echar menos" era la forma habitual en la época de nuestro "echar de menos". "Echarás de menos tus raíces, porque te daban la firmeza y la seguridad que ahora añoras".

[vv. 47-48] La lluvia que acompaña a la tempestad tendrá un efecto muy distinto de aquella que regaba el árbol y lo hacía crecer. Así, paradójicamente, la nave echará de menos los lazos que coartaban su libertad y tendrá miedo de la lluvia que era fuente de vida en su antigua existencia.

No invidies a los peces sus moradas;

50 mira el seno del mar enriquecido de tesoros y joyas, heredadas del codicioso mercader perdido: más vale ser sagaz de temerosa, que verte arrepentida de animosa.

[v. 49] "Envidiar sus moradas a los peces" es desear ahogarse.

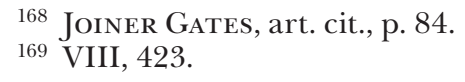


[v. 50] "el seno del mar": las profundidades marinas. La nave debe aprender prudencia contemplando las riquezas que han ido a parar al fondo del mar a causa de los naufragios. El mar, metafóricamente, se ha "enriquecido" con lo que ha "heredado" del mercader codicioso.

[vv. 53-54] "Más vale que el temor te haga ser prudente a que la temeridad te obligue a arrepentirte".

55 Agradécele a Dios, con retirarte, que aprisionó los golfos y el tridente para que no saliesen a buscarte; no seas quien le obligue, inobediente, a que nos encarcele en sus extremos,

60 porque, pues no nos buscan, los dejemos.

[vv. 55-56] La nave tiene que "retirarse" del mar para agradecer a Dios que haya "retirado" o "aprisionado" al mar para que éste no invada la tierra, según la cosmovisión bíblica: “¿Quién cerró con puertas el mar / cuando impetuoso salía del seno... / dándole yo la ley / y poniéndole puertas y cerrojos, / diciéndole: De aquí no pasarás?” (Job, 38, 8-11) y “¿No me temeréis a mí... / que de arenas he hecho un muro para el mar?” (Jeremías, 5, 22). Cf. también Salmos, 104, 9 y Proverbios, 8, 29.

La imagen se repite frecuentemente en la patrística: "Mare, quod tanto conmotionis suae vertice fertur et elevatur ad nubes, frenant tenues arenas, ut videamus potestatem tantam non pulveri cedere, sed praecepto"170. La misma observación aparece en fray Luis de Granada:

Y cierto es cosa de admiración que, corriendo todos los elementos con tan grande ímpetu a sus lugares naturales, como ya dijimos, y siendo natural lugar del agua estar sobre todo el cuerpo de la tierra, y tenerla cubierta, haberla Dios, con su sola palabra sacado de este lugar, y conservándola tantos mil años fuera dél, sin usurpar ella un paso del espacio que le señaló. Lo cual trae él por argumento para confundir la desobediencia y desacato de los hombres, vista la obediencia de las criaturas inservibles ${ }^{171}$.

Partiendo de estas ideas, Pedro Mejía llega a preguntarse si es lícito buscar causas naturales para el hecho de que el mar no invada la tierra:

170 San Pedro Crisólogo, Opera Omnia, PL, t. LII, 1864, vol. 4, p. 64.

171 Introducción del Símbolo de la Fe, ed. J.M. Balcells, Cátedra, Madrid, 1989, p. 217. 
Y puesto que por ventura fuese verdad que haya algunas estrellas cuya influencia ayude y participe en esta obra y efecto... todavía no lo osaría yo afirmar, pues la Santa Escritura no hace de tal cosa mención, antes todo absolutamente lo atribuye a Dios... Y pues esta obra y milagro se debe atribuir a solo Dios, no hay para qué busquemos otras razones ni causas en la tierra ni en el cielo ${ }^{172}$.

El tema aparece en la poesía de fray Luis: "las lindes y señales / con que a la mar hinchada / la Providencia tiene aprisionada"173 y en un soneto de Medrano: "A humilde playa / Dios, el que admiras piélago insolente, / rindió, y 'ésta', le dijo 'sea tu raya': / jamás de aquí con ambicioso antojo / oses pasar"174. Véase, también, "Qual de l'arena più minuta, o vile / O debil cosa più trovar potreste? / O qual più violenta e più superba / De l'orgoglioso mare? E pure a freno / L'arena tien del mar l'orgoglio e l'ira”175; ";Oh valor verdadero / de tu brazo, que el bravo mar enfrena, / y quebrantas su brío, / no en montañas de acero, / sino en una menuda y floja arena!"176; "Quise ver el mar sagrado... / que con un freno de arena / le detiene Dios el paso" "177; "El que con arena débil / al libre mar puso freno"178; "que quien detiene el mar con blanda arena / la pompa humilla, y la ambición enfrena"179; "Del mar azul la diáfana hermosura... / que es su muro la arena mal segura"180; “¿Quién puso al mar en las arenas tasa, / cuando furioso, con soberbio empeño, / a ser vecino de los montes pasa?"181; "como el freno del mar la arena algente / de muralla le sirve en su ribera, / en el término mismo que la puso / el que lugar y centro le dispuso" 182; "Y ¿sobre qué pusiste / la inmensa madre tierra, / que embraza montes, que provincias viste, / que los mares

172 Diálogos o coloquios, ed. A. Castro Díaz, Cátedra, Madrid, 2004, p. 475.

173 Poesía, ed. cit., p. 69.

${ }^{174}$ Op. cit., p. 286, con nota donde el editor aduce, además de los precedentes bíblicos, unos versos de Boecio en La consolazione della filosofia, ed. O. Dallera, Rizzoli, Milano, 1977, II, 8, los de fray Luis y el soneto 32 de Quevedo.

175 T. Tasso, Il mondo creato, ed. G. Petrocchi, Felice Le Monnier, Firenze, 1951, III, vv. 354-358.

${ }_{176}$ Pedro Malón de Chaide, La conversión de la Magdalena, ed. P. Félix García, Espasa Calpe, Madrid, 1959, t. 1, p. 107.

${ }_{177}$ Lope De Vega, El vaso de elección, san Pablo, jornada 1, consultado en la Biblioteca Virtual Miguel de Cervantes.

${ }^{178}$ Lope De Vega, Pastores de Belén, ed. A. Carreño, PPU, Barcelona, 1991, p. 410.

179 Lope de Vega, Corona trágica, en Poesías completas, ed. A. Carreño, Turner, Madrid, 2005, t. 5, I, 16; cf. Alessandro Martinengo, "Bibbia ws. Omero: il tema del mare e della navigazione nella poesia morale di Quevedo", StI, 3 (1985), p. 92, donde recuerda que Alberto Lista observó que de este verso de Lope procede el de RACINE: "Celui qui met un frein à la fureur des flots / Sait aussi des méchants arrêter les complots" (Athalie, I, vv. 61-62).

180 J. DE VAldivielso, Vida de san Josef, ed. cit., p. 141.

181 Príncipe de Esquilache, Obras en verso, Amberes, 1654, p. 42.

182 Conde de Villamediana, Poesía impresa completa, ed. cit., p. 558. 
encierra / y con armas de arena los resiste?"183; "las aguas que, obedientes, se volvían a encarcelar con las llaves de arena que les impuso su Eterno autor"184.

La imagen, con el uso reiterado de la frase "ley de arena", aparece con frecuencia en Quevedo: "antes que aprisionase en la orilla las impaciencias del mar, para que tan revoltoso elemento obedeciese la ley escrita en la arena"185; "la obediencia del ímpetu del mar a la ley que se le escribió en la arena"186; “Quién vio la soberbia del mar amotinada con las cóleras rabiosas del viento llegar a la orilla... y besar humilde la ley que se le escribió en la arena?"187; "Derribó el globo superior y impetuoso del agua a las concavidades profundas, aprisionando las cóleras de sus borrascas impacientes de límite con prisiones débiles de arena"188; "Que, obedeciendo su soberbia procelosa, la cárcel de flaca arena en que se cierra le amonestó que obedeciese la que en ella le puso Dios, con sus golfos"189; "La voluntad de Dios por grillos tienes, / y ley de arena tu coraje humilla"190; "fiado / en la ley que está escrita con arena..."191.

[v. 56] "Golfos": "en vulgar castellano siempre entendemos golfo por mar profundo, desviado de tierra en alta mar"192.

[v. 56] El tridente es atributo de Neptuno, pero a veces, en el lenguaje poético funciona como metonimia de mar: "Apenas fui del húmido tridente / en tus piadosas manos arrojado..."193; "las espumas del húmedo tridente / las orillas peinaban"194; "vieron... / una lancha tras él llena de gente / romper la plata al húmido tridente"195; "el

183 P. EspinosA, op. cit., p. 115.

184 Sor JuAna InÉs de la Cruz, Inundación castálida, ed. cit., p. 399.

185 Obras en prosa, ed. F. Buendía, Aguilar, Madrid, 1974, p. 1303.

186 Obras completas en prosa, ed. cit., t. 4, p. 381.

187 Obras en prosa, ed. cit., p. 1543.

188 La caída para levantarse, ed. V. Nidier, Giardini, Pisa, 1994, p. 198.

189 Virtud militante, en Obras completas en prosa, ed. cit., t. 4, p. 505.

190 Obra poética, ed. cit., t. 1, núm. 107.

191 Locuras de Orlando, núm. 875, I, vv. 786-787. Sobre este tema, véase ÁNGEL Sierra de Cózar, "Autores latinos en los poemas morales de Quevedo: reescrituras y cronología”, Humanitas in honorem A. Fontán, Gredos, Madrid, 1992, pp. 12-14 y Alessandro Martinengo, "El topos del mar aprisionado: Quevedo lector de fray Luis", en Siglos dorados. Homenaje a Augustin Redondo, Castalia, Madrid, 2004, t. 2, pp. 903-914.

192 S. De Covarrubias, Diccionario de Autoridades, ed. facs., Gredos, Madrid, 1984.

193 Vicente Espinel, Diversas rimas, eds. A. Navarro González y Pilar González Velasco, Universidad, Salamanca, 1980, p. 88.

194 Lope de Vega, Laurel de Apolo, ed. C. Giaffreda, Aliena, Firenze, 2002, p. 260.

195 Lope, La Dragontea, ed. cit., p. 537. 
arte enseño / que asegura el vago leño / en las iras del tridente"196; “¡Oh tú, de los altos mares / y de más que inmensos golfos / del espumoso tridente, / señor absoluto, Eolo!"197; "Las velas dimos al feroz tridente"198; "Si las argivas tierras el tridente / libre pudo dejar de inundaciones"199. Góngora dice: "Abetos suyos tres aquel tridente / violaron a Neptuno" 200 , que Jammes explica así: "Aquel tridente: 'aquella provincia'. El tridente es, para Neptuno, lo mismo que el cetro para los otros reyes, el símbolo de su poder, y se puede por consiguiente emplear por metonimia para designar sus reinos"201. Parecen parodiar estos versos de Góngora los de Agustín de Salazar y Torres que dicen: "Callen cuantos abetos / el húmido tridente / sulcaron de Neptuno" 202 .

[vv. 58-60] Estos versos me resultan incomprensibles. Creo que "inobediente" se refiere al navío, que incumpliendo las leyes naturales se va en busca del peligro; pero también pudiera aludir a la posibilidad de que el mar sea en algún momento inobediente a la ley que le puso Dios de no invadir la tierra. El pronombre "le" puede tener como antecedente a "Dios", pero también a "mar". En cualquier caso, no acabo de entender qué significa exactamente "que nos encarcele en sus extremos".

No aguardes que naufragios acrediten, a costa de tus jarcias, mis razones; deja que en paz sus campos los habiten los nadadores mudos, los tritones:

65 mas si de navegar estás resuelta, ya le prevengo llantos a tu vuelta.

[vv. 61-62] "No esperes a que la realidad me dé la razón”.

[v. 63] "sus campos": creo que el antecedente de "sus" no es ninguna de las palabras anteriores, sino una referencia general a todo lo anterior, de manera que el sentido sería "los campos del mar".

[vv. 63-64] "Deja que los habitantes propios del mar vivan en él, y no vayas como un intruso a perturbar su tranquilidad". Los "nada-

196 Conde de Villamediana, Poesía inédita completa, ed. J.F. Ruiz Casanova, Cátedra, Madrid, 1994, p. 129

197 L. Carrillo y Sotomayor, op. cit., p. 31.

198 Juan Rufo, Las seiscientas apotegmas, ed. A. Blecua, Clásicos Castellanos, Madrid, 1972, p. 319.

199 Sor Juana Inés de la Cruz, Inundación castálida, ed. cit., p. 399.

200 Soledades, ed. cit., t. 1, vv. 413-414.

201 En su ed. a las Soledades, de Góngora, p. 280.

202 En R. Andrés, Tiempo y caída, Sirmio, Barcelona, 1994, p. 234. 
dores mudos" son, naturalmente, los peces, uno de cuyos atributos canónicos es el silencio. La frase "nadadores mudos" viene de Lucrecio: "mutaeque natantes" ${ }^{03}$. Rioja traduce todavía más ceñidamente cuando dice: "quien no desea / ser, cual yo, pasto de nadantes mudos"204.

[v. 64] "tritones": "pez fingido, con figura de hombre de medio cuerpo arriba, que las fábulas fingen semidioses del mar" (Dicc. Aut.).

EnriQue Moreno Castillo

Universidad Autónoma de Madrid-IULCE

${ }^{203}$ De rerum natura, II, 342.

204 Op. cit., ed. de B. López, p. 157. Véase Daniel Devoto, "Mudo como un pescado", en Textos y contextos, Gredos, Madrid, 1974, pp. 170-187. 


\section{APÉNDICE}

\section{Príncipe de Esquilache}

\section{CAAnCión II}

\section{A LA NAVE}

¿Adónde vas, del viento acompañado, a tan dudoso fin, errante pino, con tantas amenazas engañado, por tantas inclemencias peregrino?

5 No rompas mal seguro de opuestas aguas el soberbio muro, y tu desgracia vuelva risa del mar la gloria de la selva, ni esperes que el mudable viento altivo,

10 viéndote inútil tronco fugitivo, se acuerde, menos fiero, que fue lisonja de tu abril primero. Y si el rigor en la espesura ablanda, al monte ruega y a las olas manda.

Armado contra el brazo del estío, libraste de su injuria al caminante, y opuesto al sol tu cóncavo sombrío, su eterna luz le respetó constante; y ahora al reino cano,

20 en la tirana fe del océano, te entregas solo y mudo, de tu hermosura y altivez desnudo, y tienes de oro y de esperanzas llena a la codicia inútil de su arena,

25 y sus ocultos senos guardan por ti depósitos ajenos, y como el mismo que recibe el daño eres del mar habitador extraño.

Vagante osado por región tan nueva,

30 alientas de los hombres la codicia que sobre espumas frágiles te lleva más que del viento la inquietud propicia, no mirando en los mares, antes que el seno de sus campos ares,

35 que sin firmeza alguna, a ruegos de la industria y la fortuna, ajeno yugo en la cerviz consiente por breve tiempo la soberbia frente, no siendo naturales

40 de la estéril región de sus cristales el lino, el hombre, el leño, que encamina soplo extranjero a su fatal ruina. 
¿De qué razón, de qué piedad confías tu incierta vida? ¿Qué obligó al piloto

45 velar las noches y temer los días y hacer a veces el postrero voto? Y cuando más alcanza es el menor peligro la bonanza. Y tú que osado quieres

50 buscarle siempre, entre sus brazos mueres. ¿Qué mal temida perdición te obliga a contrastar de tantos la fatiga? ¿O qué, engañado, medras, surcando arenas y besando piedras?

55 Y mal experto en tu quietud, previenes con daño propio los ajenos bienes.

Si un tiempo fuiste albergue de las aves, mejor pudieras en los dulces nidos, al blando son de sus tristezas graves,

60 oír lisonjas que escuchar bramidos del importuno viento en las trágicas voces de su aliento, siendo en tu suerte varia tu misma madre tu mayor contraria,

65 que si llegar pretendes a sus brazos, al mar te entrega en míseros pedazos, con lamentables señas en las funestas manos de las peñas y cuando más tu diligencia paga

70 te vuelve al monte de su arena vaga.

Canción, la primer nave, por dudosa jornada, que no sabe, descansa del camino; descanse pues mi pluma entre su lino ${ }^{1}$.

[v. 5] "mal seguro": la misma expresión emplea fray Luis de León: "los daños del veneno / que bebí mal seguro" ". Lapesa, hablando sobre los cultismos semánticos de fray Luis, señala el uso de "mal como primer elemento de composición", calcado del latín, tal como aparece, por ejemplo, en "digito male pertinaci" de Horacio. Dámaso Alonso señala esta construcción como característica del estilo de Medrano ${ }^{3}$. Compárese con "En estos días, cuando andaba celoso y mal seguro...";; ";Oh mal seguro bien, oh cuidadosa / riqueza!" ; Góngora, habla de "la planta mal segura" de una ninfa ${ }^{6}$ y Quevedo dice: "Ícaro en senda de oro mal segura" (núm. 449).

1 Obras en verso, Amberes, 1654, pp. 266-268.

2 Poesía, ed. Ramajo Caño, Círculo de Lectores, Barcelona, 2006, p. 93.

${ }^{3}$ Francisco de Medrano, Poesía, ed. D. Alonso, Cátedra, Madrid, 1988, p. 9.

${ }^{4}$ M. Cervantes, La Galatea, eds. F. Estrada y M.T. López García-Berdoy, Cátedra, Madrid, 1995, p. 473.

${ }^{5}$ F. DE Rioja, Poesía, ed. B. López Bueno, Cátedra, Madrid, 1984, p. 172.

${ }^{6}$ Sonetos, ed. B. Ciplijauskaité, Castalia, Madrid, 1978, p. 136. 
[v. 7] "no sea que tu desgracia convierta lo que fue gloria de la selva, el árbol que hubo en un principio, en risa o burla del mar."

[vv. 13-14] Aunque el viento ablanda su rigor en la espesura (de la copa del árbol o del bosque en general), hay que tener en cuenta que la actividad del viento en el monte puede considerarse un ruego, mientras que en el mar tiene la fuerza de una orden o mandato. Realmente sería más lógico que el v. 13 empezara por "que" en vez de "y".

[v. 15] "Armado contra el brazo del estío": armado con armas defensivas frente al poder del calor del sol. Compárese con el v. 15 de la "Exhortación" de Quevedo y con el soneto 19 de Rioja.

[v. 16] "Libraste al caminante de la injuria, de la ofensa o molestia del calor del sol".

[v. 17] "cóncavo sombrío": la copa del árbol.

[vv. 23-24] "Tienes llena de codicia a su arena, que está deseando recibir los restos del naufragio. Esta codicia es inútil, pues no se podrá aprovechar de esas riquezas". La arena, aquí, más que la de la playa, es la del fondo del mar.

[vv. 25-26] El fondo del mar guarda en depósito riquezas ajenas.

[vv. 30-32] "Sobre las espumas frágiles te lleva la codicia más que la propicia inquietud del viento".

[v. 34] "Arar" como metáfora de "navegar" aparece ya en la poesía latina ${ }^{7}$ y es muy frecuente en la poesía del Siglo de Oro.

[vv. 36-38] "la soberbia frente del mar no consiente un yugo ajeno en la cerviz". El yugo es el navío que pesa sobre él.

[v. 41] "el lino" del que están hechas las velas de los barcos. El uso de "lino" por "vela" se halla en Séneca: "nunc lina sinu / tendere toto, nunc prolato / pede transversos captare notos" ${ }^{8}$. Luego, esta metonimia aparece con frecuencia en la poesía de los siglos XVi y xvir: "Né sino ad ora, lasso, io veggio donde / fiato si muova, e nel mio lino spiri, / di vento destro, e così amico e fido / che mi sospinga al lido"; "Oh fortunato il fabro e quel che n' have / l'alto governo, e'l bianco lino e'l legno" 10 ; "il fero Trace... / spiega superbo i temerarii lini"11; "Alta haya de hoy más, volante lino / al Euro dé"12; "De la tranquilidad pisas contento / la arena enjuta, cuando en mar turbado / ambicioso bajel da lino al viento" (ibid., p. 96); "¿Veis... estas

${ }^{7}$ Virgilio, Eneida, ed. M. Rat, Garnier, Paris, 1960, t. 2, 780; Ovidio, Tristes, J. André, Paris, 1968, III, 12, 36.

${ }^{8}$ Eurípides, Medea, vv. 320-322.

9 B. Tasso, Salmi, Rime, Ode, V, 185, consultado en la página en línea de la Biblioteca Italiana de la Università degli Studi di Roma "La Sapienza": www.bibliotecaitaliana.it.

${ }^{10}$ T. Tasso, Rime, en Opere, ed. B. Maier, Rizzoli, Milano, 1963, núm. 1l16, p. 986.

11 Giovan Battista Marino, Rime eroiche, eds. O. Besoni, A. Martini y M.C. Newlin-Gianini, Panini, Modena, 2002, p. 141.

${ }^{12}$ Góngora, Sonetos completos, ed. B. Ciplijauskaité, Castalia, Madrid, 1992, p. 81. 
que de la barra a las arenas / despliegan blanco lino...?"13; "Ulises luego entrega / el pardo lino al soplo vagoroso" ${ }^{4}$; “;Oh rotos leños y mojado lino...!" ${ }^{15}$; "Del ufano bajel, que lino al viento / dio..." ${ }^{\text {" }}$. Cf. también los versos citados del Príncipe de Esquilache en las notas 11-12 del poema de Quevedo. El Dicc. Aut. explica, en la entrada "lino", que "se toma muchas veces por la vela o velas del navío. Es más usado en lo poético".

[vv. 47-48] La bonanza sólo puede ser calificada, en el mejor de los casos, de "menor peligro". La bonanza es peligrosa porque hace que el navegante se confíe y no esté prevenido contra los peligros del mar. El tema aparece en Lucrecio, Virgilio, Ovidio, y Séneca ${ }^{17}$ y es muy frecuente en la poesía del Siglo de Oro. Quevedo lo trata en el soneto que comienza "Más escarmientos dan al Ponto fiero, / si atiendes, la bonanza y el olvido / que el peligro y naufragio prevenido" (núm. 57).

[v. 50] "buscarle": el antecedente es "el peligro". Parece haber un reflejo de la frase: "Qui amat periculum in illo peribit" (Eclesiástico, 3, 27).

[vv. 53-54] En el texto impreso hay un signo de admiración al final de esta frase. Quizá habría que interpretar “¡Oh, qué engañado medras, / surcando arenas y besando piedras!”. Me inclino por la otra interpretación, pues el verbo medrar tiene más sentido en la forma interrogativa, ya que da por supuesto que el interlocutor no consigue medrar en absoluto, mientras que en la forma exclamativa se considera que sí medra, aunque "engañado".

[v. 54] "surcando arenas": las arenas del fondo del mar como metonimia del mar en general. Pero además hay una reminiscencia de la idea de "sembrar en la arena" como sinónimo de hacer una tarea vana.

[v. 54] "besando piedras": "estrellándote contra los arrecifes".

[v. 55] "mal experto en tu quietud". "con poca habilidad para buscar tu bienestar y tu tranquilidad".

[v. 56] Aunque el avaro, aquí simbolizado por el barco, que se arriesga a los peligros del mar cree estar buscando su propio bien, en realidad está perjudicándose en beneficio de otros: de sus herederos o de quien se apropie finalmente de sus riquezas.

[vv. 57-62] Se contraponen aquí, como en el poema de Quevedo, "las lisonjas del viento" que sopla suavemente acompasándose al canto de los pájaros en la copa del árbol con los bramidos del viento tempestuoso cuando el árbol se halla ya transformado en barco.

13 Góngora, Canciones, p. 114.

14 Lope DE VEGA, Obras poéticas, ed. J.M. Blecua, Planeta, Barcelona, 1983, p. 942.

15 F. DE Rioja, op. cit., ed. de B. López, p. 219.

16 Juan de Vera Tassis, conde de Villamediana, Poesía impresa completa, ed. J.F. Ruiz Casanova, Cátedra, Madrid, 1990, p. 132.

17 Lucrecio, De rerum natura, eds. W.H.D. Rouse y M.F. Smith, Harvard University Press, 1982, II, 558-559; Virgilio, Eneida, ed. cit., V, 848-851; Ovidio, Heroidas, ed. H. Bornecque, Les Belles Lettres, Paris, 1928, VII, 53-56; SÉnecA, Cartas a Lucilio, IV, 7. 
[vv. 64-70] "tu misma madre": la tierra. La tierra es tu peor enemigo pues cuando, buscando salvación en medio de la tempestad, quieras acercarte a ella, te estrellarás contra las rocas. No entiendo bien el último verso: "te vuelve al monte de su arena vaga”.

[vv. 71-74] En el texto impreso dice: "la primera nave", que corrijo porque rompe la métrica. Tradicionalmente, se considera que la navegación comenzó con el viaje de los argonautas o bien con el arca de Noé. Pero hay cierta incongruencia entre esta última estrofa de envío y el resto del poema, en el cual no se habla del primer barco, sino de los peligros de la navegación en general. Además, en esta estrofa final parece imaginarse una nave ya desechada, como en los poemas de Carrillo y Sotomayor y de Francisco de Rioja que hemos citado arriba, mientras que en las otras estrofas se habla de una nave que está actualmente navegando. Un epigrama de Marcial (VII, 19) que es epitafio a la primera nave, la de los argonautas. Quevedo tiene un soneto sobre el mismo tema titulado "Sepulcro de Jasón el argonauta" o "A la primera nave del mundo". El lino es el de las velas pero también el lino de las sábanas sobre las que "descansa" la pluma del poeta. 
